\title{
Review on Participatory Plant Breeding
}

\author{
Wakuma Merga \\ Jimma University, College of Agriculture and Veterinery Medicine, Department of Horticulture and Plant \\ science, Post graduate Student, Jimma, Ethiopia
}

*Corresponding Author: Wakuma Merga, Jimma University, College of Agriculture and Veterinery Medicine, Department of Horticulture and Plant science, Post graduate Student, Jimma , Ethiopia

\begin{abstract}
Participatory plant breeding (PPB) is the development of a plant breeding program in collaboration between breeders, farmers, marketers, processors, consumers, and policy makers. It allow farmers to take part in the development of new varieties or populations, more suitable to marginal environments and to organic farming agronomic practices. It is based on the idea that farmers as well as professional plant breeders have important knowledge and skills that could complement one another. Plant breeders can direct their research according to the needs of the specific groups of farmers (women, men, rich and poor). Farmers participation to evaluate varieties in mother trials is most preferred at the maturity period of the crops but in Baby Trials Farmer managed, farmer inputs, farmer supervised Only perception data taken. In PPB model, generation of genetic variability is often, but not necessarily always, the responsibility of the research institution. The stapes of PPB are: Identify Target Environments And Target Users, Choice of The Target Environment And Users, Choice of Genetic Material, Choice of Parental Material, Choice of Breeding Method, Naming of Varieties And Sharing and Disseminating Findings. The Possible Outcomes of PPB are: Production gains, Biodiversity enhancement and Cost-efficiencies and effectiveness. PPB have the following Advantage Over Conventional Plant Breeding Methods: At least one parent in any cross is well adapted to the local environment, Genotypes $x$ environment interactions are used positively because breeding is done in the target environment and The impact of genotype $x$ year interaction is probably reduced because local parental materials have adapted to local year-to-year variations.
\end{abstract}

\section{INTRODUCTION}

Participatory Plant Breeding (PPB) is based on the idea that farmers as well as professional plant breeders have important knowledge and skills that could complement one another(Bhargav et al., 2014). PPB is also defined as a range of approaches that involve a mix of actors (including scientists, breeders, farmers and other stakeholders) in plant breeding stages(Probst, 2016).

Broadly, participatory plant breeding (PPB) is the development of a plant breeding program in collaboration between breeders and farmers, marketers, processors, consumers, and policy makers (food security, health and nutrition, employment)(Ceccarelli, 2012). In the context of plant breeding in the developing world, PPB is breeding that involves close farmer-researcher collaboration to bring about plant genetic improvement within a species. PPB is a strategy for plant breeding with its own set of methodologies that applies in situations where the demand for specific varietal traits among producers, traders, industries and consumers is poorly understood and difficult to diagnose with conventional market research methods. Depending on who controls the breeding process (researchers or farmers) and the scale on which the work is undertaken (community-centered or research to extrapolate results) two broad categories are usually differentiated: 'farmer-led' and 'formal-led' PPB(Probst, 2016).

PPB programs allow farmers to take part in the development of new varieties or populations, more suitable to marginal environments and to organic farming agronomic practices(Malandrin and Dvortsin, 2013). It is a complement to conventional breeding approaches. It is seen by several scientists as a way to overcome the limitations of conventional breeding by offering farmers the possibility to decide which varieties suit better their needs and conditions without exposing the household to any risk during the selection progress. A number of PPB varieties have been already released for many crops e.g. rice, maize, sorghum, barley, etc(Bhargav et al., 2014). PPB has evolved mainly to address the difficulties of poor farmers in developing countries. Widely seen as having 
advantages for use in low yield potential, high stress environments, It is most often applied when specific adaptation is sought(Ceccarelli, 2012).

In Conventional Plant Breeding (CPB) new varieties are released before knowing whether the farmers like them or not and the process is typically supply-driven. In Participatory Plant Breeding (PPB) the delivery phase is turned upside down because the process is driven by the initial adoption by farmers at the end of a full cycle of selection and is therefore demand-driven. (Nelson et al., 2015, Bhargav et al., 2014, Ceccarelli, 2016). So that Participatory research is now seen by many as a way to address the problems of most agricultural research programmers, as PPB is expected to produce varieties that are targeted, relevant and appropriate (Bellon, 2006). So that the Goals of PPB are: To Increase production and profitability of crop production through the development and enhanced adoption of suitable, usually improved, varieties. To Provide benefits to a specific type of user, or to deliberately address the needs of a broader range of users and To Build farmer skills to enhance farmer selection and seed production efforts(Bhargav et al., 2014). Therefore, Participatory plant breeding includes many activities like :- identifying breeding objectives, generating genetic variability, selecting within variable populations to develop experimental varieties, evaluating experimental varieties, variety release, popularization of release varieties, and seed production(Bhargav et al., 2014).

Development projects can support farmer-led PPB through: Germplasm support to increase farmers' access to diversity, combined with testing new material, and supporting seed systems; Skills support in breeding, testing or seed production; Support in forming links and networks to exchange material or information; Indirect support to confront barriers to farmer-breeding, or help promote PPB in other ways, such as market development(Probst, 2016). The objective of this paper is to review about participatory plant breeding.

\section{Participatory Plant Breeding (PPB)}

Participatory Plant Breeding (PPB) is based on the idea that farmers as well as professional plant breeders have important knowledge and skills that could complement one another. It is approaches that involve a mix of actors in plant breeding stages(Probst, 2016). For more than 5,000 years men and women farmers have been domesticating various plant species and developing a wide range of crop varieties that fit their specific needs and respective environmental conditions. Only in the last 100 years has specialized plant breeding undertaken by formal institutions emerged. Today most farmers still prefer their own seed where formal breeding and seed systems fail to supply planting material of suitable quality and diversity in a timely manner and at accessible prices(Probst, 2016).

PPB is "participatory" because users can have a role in all major stages of the process of plant breeding and variety selection(Enjalbert et al., 2011) It is a logical extension of participatory varietal selection. If it is desirable to involve farmers in selection of cultivars then there is no need to wait until there are finished products. Farmers can be involved in selecting among segregating material(Singh et al., 2014)

The implementation of a PPB program implies not only a change in the process of variety release but also assumes changes in the seed sector. Conventional plant breeding and the formal seed industry have been successful in providing improved varieties and seeds of some important staple or cash crops to farmers in favorable areas of developing countries. The diverse needs of the small-scale farmers in marginal environments and remote regions prompting new paradigms in plant breeding and seed supply systems(Ceccarelli et al., 2007).

The true PPB programme is a dynamic process in which both the roles of partners and the extent and the manner in which they collaborate change with time. Implicit in this definition is that farmer breeding, in which scientists or other stakeholders have no part, is not considered as a PPB programme. It is also important to mention that a truly participatory programme is necessarily inclusive in relation to gender and has an empowering effect on the participants(Ceccarelli, 2012).

\section{Kinds of Participation in PPB}

\section{Functional Participation}

Plant breeders can direct their research according to the needs of the specific groups of farmers (women, men, rich and poor). Farmers can assure plant breeders that they are assessing tradeoffs among traits correctly. On-farm research assures that varieties will produce well under "real life" 
conditions. On farm research can be managed by the researcher, by the farmer, or by both. PPB ensures greater success of adoption of innovation by the farmers(Bhargav et al., 2014).

\section{Empowering Participation}

By Increasing farmer knowledge and skills so that farmers can participate more fully in the collaborative breeding efforts and be better at their own, personal efforts(Bhargav et al., 2014).

\section{Stage of Farmers Participation and Roles of farmers in PPB}

Farmer participation can usefully occur at various times, depending on the crop, parent materials, target region, researcher capacity to assimilate farmer criteria, farmer capacity to handle different types of materials, traits of interest, and scale of the breeding program/number of materials to be screened(Bhargav et al., 2014).

The possible roles of farmers in participatory plant breeding are ; provide technical leadership, provide key social organizational leadership, information giving role, trainer/skill builder role, field laborer role, input supply role and provide landrace or farmer material used for further breeding work(Bhargav et al., 2014).

\section{Participatory Variety Selection (PVS)}

Participatory Variety Selection (PVS) is a process by which the field testing of finished or nearly finished varieties, usually only a limited number, is done with the participation of the partners(Ceccarelli, 2012). Selection is the key activity in any breeding program and it occurs at all stages of the breeding process(Rahman et al., 2015). Therefore PVS is always an integral part of PPB. It can also stand alone(Ceccarelli, 2012)

Involvement of partners during the last stage of an otherwise non-participatory breeding programme has one major advantage and one major disadvantage: the advantage is that, if the partners' opinion becomes part of the release process which follows the on-farm trials, only the varieties that partners like will be proposed for release, thus increasing enormously the speed and the rate of adoption; the major disadvantage is that because partners' opinion is sought at the very last stage of the breeding programme there may be nothing left among the varieties tested in the on-farm trials that meets partner expectations. This disadvantage may induce the breeder to seek partner participation at an earlier stage of the breeding programme (Ceccarelli, 2012).

Participatory varietal selection can be used effectively to identify farmer-acceptable varieties and thereby overcome the constraints that cause farmers to grow old or obsolete varieties(Rahman et al., 2015). PVS may also be used as a starting point, a sort of exploratory trial, to help partners assessing properly the amount of commitment in land and time that a fully fledged PPB programme requires(Ceccarelli, 2012).

\section{PVS Based on Mother and Baby Trails}

\section{Mother Trials}

Many cultivars (6-10 in general) and one local check

Several locations, one replicate per location/ more depending upon variation in location

Researcher design, farmer-managed, farmer level of inputs

Quantitative data collected by researchers

Ranking of varieties (preference analysis/matrix ranking)

Farmers participation to evaluate varieties in mother trials is most preferred at the maturity period of the crops

\section{Baby Trials}

One or two new cultivars per farmer-compared to local cultivar/many trials

Usually for a variety in mother trial 4-5 baby trials per location/village

Seed is provided in a sufficient quantity (about 0.5 to $1 \mathrm{~kg}$ ) to the farmers

Farmer managed, farmer inputs, farmer supervised Only perception data (basically no yield and other quantitative data) 


\section{A General Model of Participatory Plant Breeding}

In PPB model, the first step (generation of genetic variability) is often, but not necessarily always, the responsibility of the research institution. It should be noted that when the genetic variability is created by making crosses, there is a substantial difference between making crosses, choosing the parents and designing the crosses. Making a cross is a purely technical operation, while choosing the parents and designing the crosses is a key decision in a breeding programme. In a breeding programme, a large part of the parental material used in crosses is represented by the best breeding material selected from the previous breeding cycle, and because in PPB the selection is done by both breeders and farmers, farmers do in fact participate in the choice of the parents to begin a new breeding cycle. A number of stages of selection are conducted in farmers' fields with the participation of farmers and other stakeholders, with continuous interaction with the research institute and with other farmers involved in the PPB programme. The selection is conducted independently in each location. This generally leads to the selection of different entries in different locations but does not exclude selecting the same material(Ceccarelli, 2012).

The best breeding material produced after the four stages of selection can be used by farmers as varieties and by the research institute as parental material for crosses to begin a new breeding cycle. It is important to notice that different locations may receive different types of germplasm of the same crop and select different varieties and that interaction among farmers may depend on their geographical location as well as communication technologies, etc(Ceccarelli, 2012).

In the case of self-pollinated crops and when the breeding method is the pedigree method, the selection in farmers fields can start with the segregating populations (for example, F2- derived F3 families) after their number is reduced by selection (including MAS) on station for disease resistance, for traits with high heritability or for quality traits such as malting quality, or a combination. Distributing different segregating populations to different locations according to farmer preferences is an additional strategy to further reduce the amount of breeding material in any one farmer's field(Ceccarelli, 2012). When the breeding programme uses the bulk-pedigree method, it is possible to start the field testing as early as the F3 bulks. In both cases, the yield testing should continue for at least four consecutive cropping seasons to generate sufficient information on the stability and performance of the breeding material for farmers to make a decision about adoption and for the variety release process (Ceccarelli, 2012). In the case of population improvement of cross-pollinated crops, the recombination phase corresponds with the creation of genetic variability, which can be done on station while the selection and testing can be done in farmers' fields (Ceccarelli, 2012). In the case of hybrid development, the creation and enrichment of breeding populations can be done. The production of uniform inbred lines to use as parents of hybrid cultivars can equally well be done on station or in farmers' fields. The advantage of developing inbred in farmers' fields is that selection during the inbreeding process is done in the real production environment, making sure that field heterogeneity does not bias the selection. Similarly in the case of test crosses, they can be more efficiently evaluated in farmers' fields. While the actual production of the hybrid seed can be done both on station and in farmers' field, the former has the advantage of not using farmers' land and farmers' labor. In the case of self-pollinated crops, targeting germplasm to farmer preferences is an additional strategy to reduce the amount of breeding material under selection and testing at any one site (Ceccarelli, 2012).

In the case of vegetative propagated crops after the initial crosses, all the subsequent generation are suitable for testing and selection in farmers' fields. As in the case of the pedigree method for selfpollinated crops, the number of clones can be reduced on station by selecting for traits such as disease and or pest resistance, for traits with high heritability, and quality traits (Ceccarelli, 2012).

The four Breeding stages (Stage 1, Stage 2, Stage 3 and Stage 4) are conducted in farmers' fields with the participation of farmers and other stakeholders. The type of breeding material depends on the type of crop and on the breeding method. The best breeding material produced after the four cycles of selection can be used by farmers as varieties, and by the research institute as parental material for crosses to begin a new breeding cycle(Ceccarelli, 2012). 


\section{Stapes of PPB}

\section{Identify Target Environments and Target Users}

The most obvious criterion for the choice of the target physical environments, is the representativeness of the major production areas for a given crop .In terms of climatic conditions (temperature, rainfall, elevation), agronomic practices, soil types, landscape, etc. The criteria for the choice of the socio-economic environments are closely interconnected with those of the target users. The programme has therefore to decide whether to work for all the various socio-economic environments present in the target area, or to privilege the most difficult environments where farmers have fewer opportunities for market access and where most of the agricultural products are used within the farms or within the community, or to work only for the most favorable, high potential, environments possibly market oriented(Ceccarelli, 2012).

The main criteria for identifying farmers can be grouped in three broad categories:

- Farmer Characteristics These include language, religion, ethnicity, age, gender, income, education, market relations or orientation, membership in farmer organizations and relationships among groups within the same community and between communities(Ceccarelli, 2012).

- Farmer Expertise This includes the need to understand whether farmers are already practicing some types of plant improvement, as this is essential in the choice of the breeding methodology(Ceccarelli, 2012).

- Farmer Needs These include the needs of different groups, their perception of risk and hence the type of variety they consider most appropriate in term of stability and yield and the need for special quality attributes for either feed or food, or both. These include also the farmers' understanding of production limitations with reference to the use of fertilizers, appropriate rotations and irrigation. It is also important to understand farmers' needs in terms of seed supply, because it makes a large difference whether the farmers predominantly use their own seed or usually buy seed from the formal sector(Ceccarelli, 2012).

\section{Choice of the Target Environment and Users}

Once the criteria are set, the actual choice of locations and users requires the involvement of partners who have very good knowledge of both the environment and the users. These are typically the staff of the extension service or the provincial research stations. The first step is to set meetings with all the stakeholders with the objective of identifying partners and locations(Ceccarelli, 2012).

\section{Choice of Genetic Material}

The type of genetic material to be used in the programme needs to be discussed with the farmers. Initially, the scientists may find that farmers are not aware of the diversity within the crop, and in this case our suggestion is to start with a wide array of genotypes representing as wide range of diversity as possible. But there are cases where farmers have previous experience with various type of germplasm and they may feel very strongly concerning one or more types of specific germplasm type (Ceccarelli, 2012).

\section{Choice of Parental Material}

The choice of parental material is of critical importance in a breeding programme and it depends largely on the number of target environments and objectives. Here we only add that, as in a CPB, the parental material in a PPB programme is, with few exceptions, the best material selected by farmers in the previous cycle(Ceccarelli, 2012).

\section{Choice of Breeding Method}

The breeding method is only one of the factors determining the success of a breeding programme; others include the identification of objectives and the choice of suitable germplasm In PPB, the choice of the breeding methods cannot be made without considering whether and how farmers are handling genetic diversity. The choice of the breeding method also depends on the desired genetic structure of the final product, i.e. pure lines, mixtures, hybrids or open pollinated varieties(Ceccarelli, 2012). 


\section{Naming of Varieties}

At the end of each cycle of the programme, if the cycle has been successful in producing a potential new variety, one issue is how to identify the variety, The naming process should be undertaken with the community. It chosen range from the name of village, name of the son or daughter of a leading farmer, or symbolic names such as peace, unity, etc. Naming of varieties has an important effect in creating a sense of ownership, and has also legal implications if PPB varieties are officially released(Ceccarelli, 2012).

\section{Sharing and Disseminating Findings}

Once the results of the PPB trials for each location have been compiled, they should be shared with all the stakeholders. This can be done through a combination of methods, including: organizing a field day at which participating farmers explain and present their work and results; documenting the work using radio and television; holding stakeholder meetings to share the results; training participating farmer groups; and producing descriptive sheets for each farmer's selected variety(Ceccarelli, 2012)

\section{Possible Outcomes/Benefits of PPB}

Production Gains: Yield increases; increases in stability of yield; faster uptake; wider diffusion; and higher market value of products(Bhargav et al., 2014).

Biodiversity Enhancement: Communities have wider access to germplasm; wider access to related knowledge; and increased inter- and intra varietal diversity(Bhargav et al., 2014).

Cost-efficiencies and Effectiveness: Fewer research dead-ends; more opportunities for cost-sharing in research; and less expensive means of diffusing varieties; higher degree of farmer satisfaction; broader range of users reached, including marginal farmers; and promotion of group learning through farm walks(Bhargav et al., 2014).

\section{Advantages of Participatory Over Conventional Plant Breeding Methods}

At least one parent in any cross is well adapted to the local environment.

Genotypes $\mathrm{x}$ environment interactions are used positively because breeding is done in the target environment.

The impact of genotype $\mathrm{x}$ year interaction is probably reduced because local parental materials have adapted to local year-to-year variations.

Only a few crosses are made, so large F2 and F3 populations can be grown to increase the likelihood of selecting desirable sergeants

The difference and similarity between CPB and PPB are
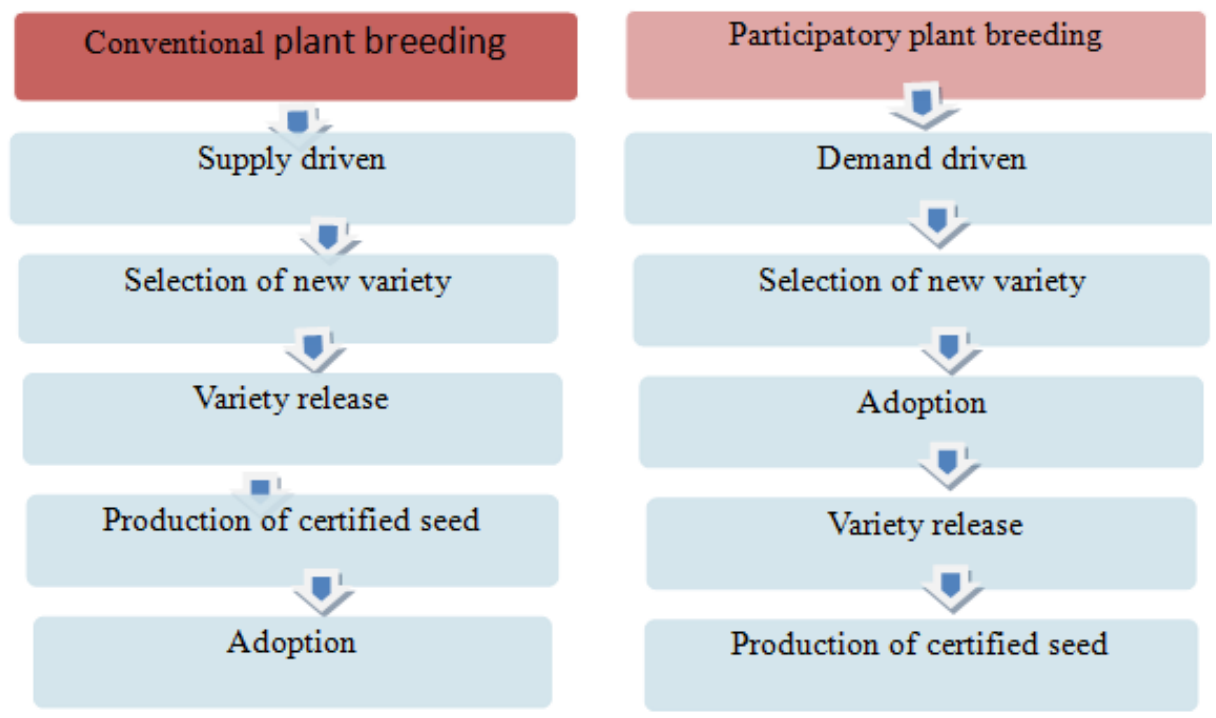

\section{SUMMARY AND CONCLUSION}

Participatory Plant Breeding is based on the idea that farmers as well as professional plant breeders have important knowledge and skills that could complement one another. It has evolved mainly to address the difficulties of poor farmers in developing countries. Generally PPB is "participatory" 
because users can have a role in all major stages of the process of plant breeding and variety selection. Participatory varietal selection can be used effectively to identify farmer-acceptable varieties and thereby overcome the constraints that cause farmers to grow old or obsolete varieties. In PVS Based there are Mother and Baby trails. Farmers participation to evaluate varieties in mother trials is most preferred at the maturity period of the crops and in a Baby trials, Farmer managed, farmer inputs, farmer supervised Only perception data was take. The recent emergence and diffusion of PPB movement is considered as a response to the weaknesses of the conventional approach to plant breeding. Decentralized plant breeding approaches based on participatory methods offer the advantages like: improved local adaptation; promotion of genetic diversity; increased breeding efficiency and empowerment of local communities. PPB also allow farmers to take part in the development of new varieties or populations, more suitable to marginal environments and to organic farming agronomic practices. The four Breeding stages (Stage 1, Stage 2, Stage 3 and Stage 4) are conducted in farmers' fields with the participation of farmers and other stakeholders. The type of breeding material depends on the type of crop and on the breeding method. In Conventional Plant Breeding (CPB) new varieties are released before knowing whether the farmers like them or not and the process is typically supply-driven. In Participatory Plant Breeding (PPB) the delivery phase is turned upside down because the process is driven by the initial adoption by farmers at the end of a full cycle of selection and is therefore demand-driven.

\section{REFERENCES}

[1] BHARGAV, D. K., MEENA, H. \& PPB, P. P. B. 2014. Participatory plant breeding: farmers as breeders. Popular Kheti, 2, 7-14.

[2] CECCARELLI, S. 2012. Plant breeding with farmers. A technical manual. ICARDA, Aleppo, Syria.

[3] CECCARELLI, S. 2016. 6 Participatory barley breeding in Syria. Farmers' Crop Varieties and Farmers' Rights: Challenges in Taxonomy and Law, 84.

[4] CECCARELLI, S., GRANDO, S. \& BAUM, M. 2007. PARTICIPATORY PLANT BREEDING IN WATER-LIMITED ENVIRONMENTS; Participatory plant breeding and drought; S. CECCARELLI, S. GRANDO AND M. BAUM. Experimental Agriculture, 43, 411.

[5] ENJALBERT, J., DAWSON, J. C., PAILlARD, S., RHONÉ, B., ROUSSELlE, Y., THOMAS, M. \& GOLDRINGER, I. 2011. Dynamic management of crop diversity: From an experimental approach to onfarm conservation. Comptes rendus biologies, 334, 458-468.

[6] MALANDRIN, V. \& DVORTSIN, L. Participatory processes of agroecological innovation in organic cereal breeding: a case study from Italy. Fourth International Scientific Symposium "Agrosym, 2013. 719725 .

[7] NELSON, C. D., BOYD, G., ROUSSEAU, R. J., CRANE, B. S., ECHT, C. S. \& JOHNSEN, K. H. 2015. Participatory genetic improvement: longleaf pine.

[8] PROBST, K. 2016. Farmers as breeders: Participatory plant breeding. Issue papers people and biodiv 2004. Part 1.

[9] RAHMAN, M., THANT, A., WIN, M., TUN, M., MOET, P., THU, A., WIN, K., MYINT, T., MYINT, O. \& TUNTUN, Y. 2015. Participatory varietal selection (PVS): a" bottom-up" breeding approach helps rice farmers in the Ayeyarwady Delta, Myanmar. SABRAO Journal of Breeding \& Genetics, 47.

[10] SINGH, Y., NAYAK, A., SHARMA, D., GAUTAM, R., SINGH, R., SINGH, R., MISHRA, V., PARIS, T. \& ISMAIL, A. 2014. Farmers' participatory varietal selection: A sustainable crop improvement approach for the 21 st century. Agroecology and sustainable food systems, 38, 427-444.

Citation: W. Merga, "Review on Participatory Plant Breeding", International Journal of Research Studies in Agricultural Sciences (IJRSAS), vol. 3, no. 9, p. 7, 2017. http://dx.doi.org/10.20431/2454-6224.0309002

Copyright: () 2017 Authors. This is an open-access article distributed under the terms of the Creative Commons Attribution License, which permits unrestricted use, distribution, and reproduction in any medium, provided the original author and source are credited. 